\title{
Optimum nutrition: thiamin, biotin and pantothenate
}

\author{
David A. Bender \\ Department of Biochemistry and Molecular Biology, University College London, Gower Street, London WC1E 6BT, UK
}

\begin{abstract}
The metabolism of glucose is deranged in thiamin deficiency, but once any deficiency has been corrected there is no further effect of increased thiamin intake on the ability to metabolize glucose through either pyruvate dehydrogenase $(E C$ 1.2.4.1) and the citric acid cycle, or the pentose phosphate pathway, in which transketolase $(E C 2.2 .1 .1)$ is the thiamin-dependent step. It has been suggested that the Wernicke-Korsakoff syndrome is associated with a genetic variant of transketolase which requires a higher than normal concentration of thiamin diphosphate for activity. This finding would suggest that there may be a group of the population who have a higher than average requirement for thiamin, but the evidence is not convincing. There are no estimates of biotin requirements, but either coenzyme saturation of erythrocyte pyruvate carboxylase, or the excretion of 3-hydroxy-isovalerate (perhaps after a test dose of leucine) could be used to assess requirements in depletion-repletion studies. Biotin deficiency leads to impaired glucose tolerance, but it is unlikely that glucose tolerance could be used to assess optimum biotin status, since other more common factors affect glucose tolerance to a greater extent. Plasma triacylglycerol and nonesterified fatty acids are moderately elevated in pantothenic acid deficiency. However, this is unlikely to be useful in assessing pantothenate status, since again, other more common factors affect plasma lipids. To date there are no biochemical indices of adequate pantothenate nutrition, and no estimates of requirements.
\end{abstract}

Thiamin status: Biotin status: Pantothenate status: Transketolase activation: Erythrocyte pyruvate carboxylase: 3-Hydroxy-isovalerate excretion

In the absence of any clear definition of optimum nutrition, and given the impracticability of performing whole-life studies, we have to investigate the metabolic functions of the nutrients in order to determine which, if any, may provide markers of a level of intake that could be considered to be desirable or optimum, rather than being simply adequate to prevent deficiency. It is also relevant to consider whether inadequate intake of the nutrient in question may be sufficiently important to warrant investigation, or whether average intakes are so obviously greater than optimum levels of intake that further investigation is probably irrelevant.

\section{Thiamin}

Thiamin has two distinct functions. Thiamin diphosphate (TDP) is the coenzyme for pyruvate dehydrogenase (EC 1.2.4.1) and transketolase (EC 2.2.1.1) in carbohydrate metabolism, $\alpha$-ketoglutarate dehydrogenase $(E C$ 1.2.4.2) in the citric acid cycle, and branched-chain keto-acid dehydrogenase (EC 1.2.4.4) in the metabolism of the branched-chain amino acids. Thiamin triphosphate (TTP) acts in nerves (and possibly also muscle) to activate a chloride ion channel.

Bettendorf et al. $(1993 b, 1994)$ showed that the formation of TTP in brain-membrane-vesicle preparations was correlated with chloride uptake. In neuroblastoma cells in culture the addition of TTP results in activation of the chloride ion channel, which is not reversed by washing out, suggesting that it acts by phosphorylation of the chloride-channel protein (Bettendorf et al. 1993a). Impaired formation of TTP may be a factor in the neurological signs of both beriberi and Wernicke-Korsakoff syndrome, although Thornber et al. (1980) reported that TTP was preserved in the brains of thiamin-deficient lambs, at the expense of TDP and free thiamin. There are no reports of TTP concentration in analyses of brains of patients with Wernicke-Korsakoff syndrome, presumably because of its instability post mortem, and at present there is no way of using TTP or membrane chloride permeability to assess thiamin nutritional status.

The role of TDP in pyruvate dehydrogenase was elucidated in the 1930s. Thiamin deficiency results in 
impaired oxidation of pyruvate, and hence accumulation of lactate and pyruvate, especially after a glucose load and moderate exercise; for many years this process was the basis of assessing thiamin nutritional status (Horwitt \& Kreisler, 1949). It is unlikely, however, that additional thiamin, above the amount required to prevent deficiency, will increase aerobic capacity and prevent the development of lactic acidosis after vigorous exercise, or that lactic acidosis after exercise can be used as an index of optimum thiamin status. In maximum exertion the limiting factor is not the activity of pyruvate dehydrogenase, but the rate at which $\mathrm{O}_{2}$ can be delivered to muscle. Furthermore, the activity of pyruvate dehydrogenase is regulated by phosphorylation and dephosphorylation in response to the intracellular $\mathrm{NADH}: \mathrm{NAD}^{+}$, acetyl-CoA : CoASH and ATP : ADP (Reed, 1976; Stryer, 1995). Webster et al. (1997) reported that supplements of thiamin $(1 \mathrm{~g}$ lipid-soluble tetrahydrofurfuryl disulfide derivative/d) had no effect on $\mathrm{O}_{2}$ uptake, plasma lactate, lactate threshold, heart rate during exercise to exhaustion, or the time to complete $2 \mathrm{~km}$ on a cycle ergometer.

$\alpha$-Ketoglutarate dehydrogenase is very similar to pyruvate dehydrogenase, and is similarly impaired in thiamin deficiency (Butterworth et al. 1993). However, there seems to be little or no impairment of citric acid cycle activity, as might be expected if there were reduced activity of this enzyme. Page et al. (1989) suggested that this lack of impairment was because the $\gamma$-aminobytyrate (GABA) shunt provides an alternative pathway. $\alpha$-Ketoglutarate can undergo transamination to glutamate, followed by decarboxylation to GABA, which undergoes transamination to succinate semialdehyde, and oxidation to succinate. They demonstrated that in the brains of thiamin-deficient rats there was significantly greater metabolic flux through the GABA shunt (as assessed by the specific activity of GABA after intracerebroventricular injection of $\left[{ }^{14} \mathrm{C}\right]$ glutamate) than in control animals. There is no simple way of assessing the activity of the GABA shunt in vivo, since the same $\mathrm{C}$ atom is lost as $\mathrm{CO}_{2}$ whether $\alpha$-ketoglutarate undergoes decarboxylation directly or by way of glutamate formation.

Thiamin deficiency also impairs carbohydrate metabolism through the pentose phosphate pathway, as a result of reduced activity of transketolase. This reduction in activity may provide the basis of a test of functional capacity, since metabolic flux through the pentose phosphate pathway, compared with that through glycolysis, can be estimated by the release of ${ }^{14} \mathrm{CO}_{2}$ from $\left[1-{ }^{14} \mathrm{C}\right]-$ and $\left[6-{ }^{14} \mathrm{C}\right]$ glucose. However, although transketolase has a significant control coefficient $(0.74)$ over the non-oxidative part of the pentose phosphate pathway (Berthon et al. 1992), the entry of glucose-6-phosphate into the pathway is controlled by glucose-6-phosphate dehydrogenase (EC 1.1.1.49), largely in response to NADPH : $\mathrm{NADP}^{+}$, and the demands of NADPH for lipogenesis and GSH reductase (EC 1.6.4.2), as well as the need for pentoses for nucleotide synthesis (Stryer, 1995). Thus, although there may be apo-transketolase in tissues, and complete saturation of the enzyme with TDP may provide an index of more than minimally-adequate thiamin status, this factor is unlikely to increase metabolic flux through the pentose phosphate pathway.

\section{The Wernicke-Korsakoff syndrome}

Impaired activity of transketolase has been implicated as a factor in the central nervous system lesions of Wernicke's encephalopathy, a condition that may be considerably more prevalent than has been believed. Harper (1979) reported that Wernicke's encephalopathy had only been diagnosed in $13 \%$ of a series of patients in whom brain lesions were detected post mortem. There is considerable international variation in the prevalence of the Wernicke-Korsakoff syndrome, which is not accounted for by variations in alcohol consumption, and a body of evidence to suggest genetic susceptibility (Zubaran et al. 1997). There are two genes for transketolase: the most investigated is on chromosome 3, but Coy et al. (1996) reported a second transketolase gene on the $\mathrm{X}$ chromosome. If this X-linked gene were associated with susceptibility to the Wernicke-Korsakoff syndrome, there would be a sex-linked (maternal) pattern of inheritance. However, most of the evidence suggests autosomal inheritance (Mukherjee et al. 1987), so it is likely that it is the gene on chromosome 3 that is important.

Blass \& Gibson (1977) reported that the affinity of transketolase for TDP was approximately 10 -fold lower in cultured fibroblasts from patients with Wernicke-Korsakoff syndrome than in those from control subjects, suggesting that there may be a genetic polymorphism in transketolase that would result in a subgroup of the population having higher than average thiamin requirements. This finding is akin to the thiamin-responsive variant of maple-syrup-urine disease, where the affinity of branched-chain keto-acid dehydrogenase is considerable lower than normal; in this case thiamin supplements of approximately $100 \mathrm{mg} / \mathrm{d}$ are required (Scriver et al. 1971).

In support of the suggestion of a variant transketolase associated with the Wernicke-Korsakoff syndrome, Jeyasingham et al. (1987) reported that a significant number of elderly patients with acute dementia, as well as chronic alcoholics, showed not only a higher than normal transketolase activation coefficient (indicative of thiamin deficiency), but also showed a further increase in enzyme activity when erythrocyte lysates were incubated with $3 \mathrm{mmol}$ thiamin/l, compared with the usual $0.3 \mathrm{mmol} / \mathrm{l}$ used for the transketolase activation test.

By contrast, Nixon et al. (1984) reported no difference in the affinity of transketolase for TDP between patients with Wernicke-Korsakoff syndrome and controls. They demonstrated a variety of different patterns of electrophoretically-separable forms of transketolase in normal subjects; one pattern was found in thirty-nine of forty-two patients with the Wernicke-Korsakoff syndrome, but only eight of thirty-six control subjects. However, Blansjaar et al. (1991) reviewed a series of investigations and concluded that there was little evidence to support a genetic abnormality of transketolase associated with Wernicke-Korsakoff syndrome.

McCool et al. (1993) and Martin et al. (1995) demonstrated that multiple electrophoretically-separable forms of transketolase were not the result of variant alleles, tissuespecific isoenzymes or differential splicing of mRNA, and suggested that there were differences in either the assembly of the functional holoenzyme or post-synthetic modification 
of the protein. Support for this suggestion comes from the studies of Wang et al. (1997), who expressed the human transketolase gene in Escherichia coli, and noted that formation of the normal active enzyme required a cytosolic factor derived from human cells, and this factor was absent from, or inactive in, cells from a Wernicke-Korsakoff patient, which showed enhanced sensitivity to thiamin deficiency in culture.

\section{Alzheimer's disease}

Perhaps partly because thiamin is effective in treating the Wernicke-Korsakoff syndrome, it has been used empirically in treatment of Alzheimer's disease and other dementias. There is some evidence to suggest that thiamin deficiency may be a factor in Alzheimer's disease.

Mastrogiacoma et al. (1993) reported low activity of $\alpha$-ketoglutarate dehydrogenase in brains from patients with Alzheimer's disease, and increased stimulation by TDP added in vitro, suggesting thiamin deficiency. Héroux et al. (1996) reported reduced activity of pyruvate and $\alpha$ ketoglutarate dehydrogenases and transketolase, as well as thiamin mono- and diphosphatases, suggesting an impairment of thiamin metabolism. By contrast, Mastrogiacoma et al. (1996) reported normal activities of thiaminmetabolizing enzymes, and normal concentrations of free thiamin and thiamin monophosphate in all three cortical regions in Alzheimer's disease. They suggested that the 18$21 \%$ reduction in TDP was due to impaired phosphorylation as a result of impaired energy-yielding metabolism.

Mastrogiacoma et al. (1993) noted a significant negative correlation between $\alpha$-ketoglutarate dehydrogenase activity and the number of neurofibrillary tangles in the cortex. Calingasan et al. (1996) reported clusters of amyloid precursor protein and amyloid-precursor-like protein in the brains of thiamin-deficient rats and mice, similar to those seen in the brains of patients with Alzheimer's disease, but noted that there was no immunochemical or histochemical evidence of amyloid precursor proteins in the brains of patients with Wernicke-Korsakoff syndrome.

There is little evidence that thiamin supplements have any beneficial effect in Alzheimer's disease; a number of studies were summarized by Blass et al. (1992) who stated that 'treatment with large doses of thiamin has not been beneficial, but the data are not wholly negative'. Nolan et al. (1991) reported no beneficial effect of $3 \mathrm{~g}$ thiamin/d over 12 months. In a preliminary report, Meador et al. (1993) stated that there was a mild beneficial effect of 3-8g thiamin/d, although there seems to have been no further report from this group. Mimori et al. (1996) reported a mild beneficial effect of $100 \mathrm{mg}$ thiamin tetrahydrofurfuryl disulfide/d.

\section{Biotin}

Dietary deficiency of biotin is more or less unknown, apart from patients on long-term total parenteral nutrition, although deficiency can be induced by consuming relatively large amounts of uncooked egg-white, in which the protein avidin binds biotin tightly, preventing its absorption. Biotin depletion also occurs in epileptics treated with several of the commonly-used anticonvulsants (Krause et al. 1985). There are no estimates of biotin requirements, and no reference nutrient intake or recommended dietary allowance; the 'safe and adequate range of intake' is derived from observed average intakes, which are, obviously, more than adequate to prevent deficiency.

There is some evidence that inadequate biotin nutrition may be a factor in sudden infant death; Johnson et al. (1980) reported that the liver biotin content in children who had died from no known cause was approximately $75 \%$ that in children who had died from a known cause. The fatty liver and kidney syndrome, which can cause sudden death of flocks of chicks, is associated with biotin deficiency (Bannister, 1976), and biotin deficiency can lead to skin and hoof lesions in pigs.

Biotin functions as the coenzyme for four carboxylases: pyruvate carboxylase (EC 6.4.1.1), acetyl-CoA carboxylase (EC 6.4.1.2), propionyl-CoA carboxylase (EC 6.4.1.3) and methylcrotonyl-CoA carboxylase (EC 6.4.1.4). Much of our knowledge of the metabolic disturbances that may be associated with biotin deficiency, and which might therefore provide sensitive markers of status, has come from studies of children with multiple carboxylase deficiency as a result of genetic diseases which lead to functional deficiency despite an adequate dietary intake. Holocarboxylase synthetase (EC 6.3.4.10) catalyses the covalent attachment of biotin to a lysyl residue in the carboxylase apo-enzymes; lack of this enzyme results in total absence of all four carboxylases, and is fatal in early life (Nyhan, 1987). When biotin-containing enzymes are catabolized, the biotin is released as biocytin (biotinyl $\varepsilon$-amino-lysine); this is normally hydrolysed by biotinidase (EC 3.5.1.12), and there is considerable conservation of the biotin released in this way. Children who lack biotinidase again suffer from multiple carboxylase deficiency, but can be treated with relatively large supplements of biotin, to replace that lost as biocytin rather than it being salvaged. However, they do suffer some long-term neurological damage (Hymes \& Wolf, 1996).

In addition to its coenzyme role, biotin also has effects on gene expression; it reacts with, and binds covalently to, histones. Biotinidase seems to be important here, acting both as an intracellular biotin-binding protein and to catalyse the covalent attachment to histones (Hymes et al. 1995; Hymes \& Wolf, 1996). There is some evidence that biotinylation of histones is important in embryological development; biotin deficiency is strongly teratogenic in experimental animals (Watanabe \& Endo, 1984; Watanabe et al. 1995).

Chauhan \& Dakshinamurti (1991) have shown that biotin also acts, relatively specifically, to induce the synthesis of glucokinase in fasted rats. Glucokinase (EC 2.7.1.2) is an isoenzyme of hexokinase (EC 2.7.1.1) with a high Michaelis constant $\left(K_{\mathrm{m}}\right)$ for glucose. In the liver, glucokinase is responsible for the increase in glucose uptake and metabolism in the fed state; hexokinase has a $K_{\mathrm{m}}$ of $0.15 \mathrm{mmol} / \mathrm{l}$, and is therefore saturated with glucose, and acting at a constant rate under all physiological conditions, whereas glucokinase, with a $K_{\mathrm{m}}$ of $20 \mathrm{mmol} / \mathrm{l}$, only has significant activity when the concentration of glucose in the portal blood rises after a meal (Stryer, 1995). Apart from the liver, the only other tissue in which glucokinase is known to be expressed is the $\beta$-islet cells of the pancreas. Froguel et al. 
(1993) studied a series of children with maturity-onset diabetes of the young (an inherited condition). They showed that these children all lacked glucokinase. While their fasting insulin secretion was more or less normal, they were unable to secrete a significantly greater amount of insulin in response to a hyperglycaemic clamp (an infusion of glucose to maintain a plasma concentration of $10 \mathrm{mmol} / \mathrm{l})$. It is likely that glucokinase acts as the initial sensor of increasing glucose concentrations for the stimulation of insulin secretion by the pancreas (Matschinsky et al. 1993). This finding suggests that biotin deficiency may be associated with impaired glucose tolerance (although the impairment of gluconeogenesis as a result of reduced activity of pyruvate carboxylase might lead to fasting hypoglycaemia), and Zhang et al. (1997) have shown that intraperitoneal administration of biotin improves glucose tolerance in rats made diabetic by administration of streptozotocin. Since the $\beta$-islet cells are destroyed by streptozotocin, this finding presumably reflects induction of hepatic glucokinase by biotin. It is, however, unlikely that glucose tolerance could be used as an index of optimum biotin status, since the interpretation of results would be confounded by impairment of insulin sensitivity in subjects developing non-insulindependent diabetes.

Pyruvate carboxylase is found in erythrocytes, and its activation in vitro by added biotin can be used as an index of status (Bitsch et al. 1985). As with other enzyme activation assays, there is normally some apo-enzyme in erythrocytes, so that it might be possible to define the level of intake at which there is $100 \%$ saturation of the enzyme, and hence an activation coefficient of 1.0. Pyruvate carboxylase is a key enzyme in gluconeogenesis, as well as being an important anaplerotic reaction for maintenance of an adequate supply of oxaloacetate for citrate cycle activity. Thus, impairment as a result of biotin deficiency might be expected to lead to fasting hypoglycaemia as a result of reduced gluconeogenesis, and ketosis as a result of lack of acetoacetate for citrate cycle activity. Fasting hypoglycaemia was proposed as the link between low biotin status and sudden infant death (Johnson et al. 1980), and impaired gluconeogenesis, which is corrected by biotin, is seen in chicks suffering from the fatty liver and kidney syndrome (Bannister, 1976). Impairment of pyruvate carboxylase activity leads to an accumulation of pyruvate, lactate and alanine (Hymes \& Wolf, 1996); however, this impairment cannot be exploited as a means of assessing optimum biotin status, since the same accumulation of pyruvate metabolites is seen in thiamin deficiency, as a result of impairment of pyruvate dehydrogenase. Furthermore, it is unlikely that intakes of biotin above those needed to prevent deficiency would increase pyruvate carboxylase activity, since the enzyme is strictly regulated by acetylCoA, which is an obligatory allosteric activator. It is only active when there is a need for synthesis of oxaloacetate for gluconeogenesis or repletion of the citrate cycle (Stryer, 1995).

Acetyl-CoA carboxylase is an essential enzyme for fatty acid synthesis and elongation, so impairment of its activity would be expected to affect acetate metabolism. Donaldson (1985) showed that in biotin-deficient chickens there was significantly less incorporation of $\left[{ }^{14} \mathrm{C}\right]$ acetate into lipids, and a greater proportion of the dose was exhaled as ${ }^{14} \mathrm{CO}_{2}$. It is unlikely that this finding could be exploited as a test of optimum biotin nutritional status. Kopinski et al. (1989) showed that the impairment of fatty acid elongation in biotin-deficient pigs with normal desaturase activity led to an increase in the monoene: saturated fatty acid value in liver lipids. While there may be similar effects on plasma lipid composition, this ratio is probably too susceptible to the effects of dietary fat intake to provide a useful index of biotin status.

Propionyl-CoA arising from a number of sources, including the metabolism of isoleucine, methionine, the side-chain of cholesterol and (rare) dietary odd-chain fatty acids, is normally carboxylated by propionyl-CoA carboxylase to yield methylmalonyl-CoA, which then undergoes isomerization to succinyl-CoA, a citrate cycle intermediate. Impairment of propionyl-CoA carboxylase leads to urinary excretion of propionate and onward metabolites such as hydroxypropionate, propionyl glycine and methyl citrate. Detection of these acids in urine may therefore provide an index of biotin deficiency; they are not normally detectable. Thus, it is possible that the ability to metabolize a test dose of $\left[{ }^{13} \mathrm{C}\right]$ propionate may provide a sensitive index of status. Barshop et al. (1991) reported that control subjects exhaled between $46 \%$ and $70 \%$ of a test dose of $\left[{ }^{13} \mathrm{C}\right]$ propionate as ${ }^{13} \mathrm{CO}_{2}$; however, apart from the endogenous sources of propionate, intestinal bacteria provide a considerable but variable amount, which would lead to unpredictable dilution of the isotope and confound interpretation of the results.

Propionyl-CoA can also compete with acetyl-CoA for incorporation into fatty acids, leading to the formation of odd-chain fatty acids. Mock et al. (1988) reported an increased proportion of 15:0 and 17:0 fatty acids in plasma lipids of patients who were biotin deficient as a result of prolonged total parenteral nutrition, which was normalized by administration of biotin. Proud et al. (1990) showed that the proportion of all odd-chain fatty acids from 15:0 to 25:0 was increased in skin lipids from biotin-deficient rats. This finding suggests that measurement of odd-chain fatty acids in skin or serum lipids might be a useful index of optimum biotin status. However, dietary intake is probably more important than endogenous synthesis of odd-chain fatty acids. Watkins (1988) measured 17:0 levels in liver and heart triacylglycerol from biotin-deficient animals fed on four different dietary sources of fat: maize oil; hydrogenated soyabean oil; a mixture of triolein, tristearin and tripalmitin; spent restaurant grease. The differences due to dietary fat were considerably greater than those due to biotin deficiency.

Methylcrotonyl-CoA is an intermediate in the metabolism of leucine; it is normally carboxylated, leading eventually to the formation of acetyl-CoA and acetoacetate. Impairment of methylcrotonyl-CoA carboxylase activity leads to urinary excretion of methylcrotonate and two onward metabolites, methylcrotonyl glycine and 3-hydroxyisovalerate. The latter acid is an early marker of experimental biotin deficiency in rats (Mock \& Mock, 1992). 3 -Hydroxy-isovalerate is normally excreted in detectable amounts (some $25-42 \mu \mathrm{mol} / 24 \mathrm{~h}$ ). In a human study in which avidin was fed in order to cause biotin depletion, Mock et al. (1997) showed that urinary 3-hydroxy- 
isovalerate excretion increased 4-fold, while plasma biotin was still (just) within the reference range. Measurement of 3-hydroxy-isovalerate excretion, perhaps combined with a loading dose of its precursor leucine, may provide a sensitive test of optimum biotin nutritional status.

\section{Pantothenate}

As with biotin, pantothenate deficiency is more or less unknown. The so-called burning foot syndrome (nutritional melalgia) in severely-malnourished prisoners of war in the Far East is often assumed to have been due to pantothenate deficiency, but for obvious reasons they were repleted with yeast extract as a source of all B-vitamins rather than being used for more precise experimental studies.

Early studies showed that there was loss of fur colour in black and brown rats fed on a pantothenate-deficient diet, and at one time it was known as the anti-grey hair factor. Despite the fact that there is no evidence that loss of hair colour with age in human subjects is related to pantothenate nutrition, it is still added to shampoos. Matsumoto et al. (1994) reported that an early sign of pantothenate deficiency in rainbow trout (Oncorhynchus mykiss) is anorexia; neither lack of anorexia nor a voracious appetite could sensibly be used as an index of optimum nutrition.

Pantothenate is pantoyl $\beta$-alanine; the next higher homologue, pantoyl $\gamma$-aminobutyrate (pantoyl GABA, homopantothenate or hopanthenate), is used in Japan to enhance cognitive function, especially in Alzheimer's disease. It acts via GABA receptors to increase acetylcholine release and cholinergic function in the cerebral cortex and hippocampus (Nakahiro et al. 1985). A rare side effect is the development of hepatic encephalopathy (Noda et al. 1991), and the excretion of a variety of dicarboxylates which arise by way of CoA-independent $\alpha$ - and $\omega$-oxidation of fatty acids (Matsumoto et al. 1991). Both the encephalopathy and the dicarboxylic aciduria are reversed by pantothenate, suggesting that homopantothenate may cause pantothenate deficiency. If this suggestion is verified, dicarboxylic aciduria may provide a marker of pantothenate status. However, it is equally possible that the adverse effects are due to a toxic action of homopantothenate which is antagonized by pantothenate.

Pantothenate has two well-defined metabolic roles: in CoA in fatty acid oxidation acetate metabolism, cholesterol and steroid synthesis, and acetylation of drugs; as the prosthetic group of acyl-carrier protein in fatty acid synthesis. Thus, it would seem that the ability to acetylate drugs such as sulphadimidine and isoniazid might be a useful test for pantothenate status, and certainly deficiency does impair drug acetylation (Pietrzik et al. 1975). There is a genetic polymorphism in the $N$-acetyltransferase (EC 2.3.1.5) that is involved in drug acetylation, and in different ethnic groups between 20 and $60 \%$ of the population are genetically slow acetylators. Vas et al. (1990) showed that the administration of $1100 \mathrm{mg}$ pantothenate daily for $7 \mathrm{~d}$ had no effect on the pharmacokinetics of sulphadimidine, and did not affect the determination of acetylator phenotype.

It is unlikely that fatty acid oxidation would be significantly affected by pantothenate status. Reibel et al. (1982) showed that despite a very considerable reduction in tissue pantothenate in deficient rats, there was little or no fall in tissue CoA. Both fasting and induction of diabetes by administration of alloxan led to similar increases in tissue CoA in control and pantothenate-deficient rats. Smith et al. (1987) did report a small fall in tissue CoA in pantothenatedeficient rats, and a greater depletion of glycogen reserves during exercise, but the deficient animals showed normal ketogenesis and ketone utilization in exercise. They noted that deficient animals became exhausted more rapidly during exercise, but this is unlikely to provide a useful test of pantothenate status for the human population at large.

The preservation of tissue $\mathrm{CoA}$ in pantothenate deficiency is presumably the result of both control over CoA synthesis and efficient conservation of phosphopantetheine arising from catabolism of CoA and acyl carrier protein. Kirschbaum et al. (1990) showed that the increase in liver $\mathrm{CoA}$ in fasting in both control and genetically-diabetic mice was due to changes in the activity of pantothenate kinase (EC 2.7.1.33). This enzyme is subject to feedback inhibition by CoA and acyl-CoA, repression by insulin (in the fed state when the need for CoA is lower) and induction by glucagon (in the fasting state when there is a greater requirement for CoA). The availability of pantothenate is unlikely to affect the rate of incorporation into $\mathrm{CoA}$, since the $K_{\mathrm{m}}$ of the enzyme is $18 \mu \mathrm{mol} / \mathrm{l}$, and even in severe experimental deficiency most tissues maintain a higher concentration. There is rapid turnover of the prosthetic group of acyl carrier protein (a half-life of the order of $6 \mathrm{~h}$ ) compared with a halflife of apo-acyl carrier protein $(6.4 \mathrm{~d}$; Volpe \& Vagelos, 1973). The phosphopantetheine released from acyl carrier protein is incorporated into $\mathrm{CoA}$, which in turn activates apo-acyl carrier protein as required; presumably the enzymes responsible for this cycling of phosphopantethine are under hormonal regulation.

Wittwer et al. (1990) showed that both plasma triacylglycerol and non-esterified fatty acids are moderately elevated in pantothenate-deficient rats; however, this finding is unlikely to provide the basis for a test of pantothenate status in human subjects.

\section{Summary}

Especially if there is a genetic polymorphism in transketolase that affects thiamin requirements, there is a need to re-examine current estimates of requirements; probably the only index of status that is available is the transketolase activation assay. While Thurnham (1981) questioned the physiological significance of marginal vitamin deficiency as determined by enzyme activation assays, transketolase activation is at least a marker that can be used to assess saturation of one physiological system.

In the case of biotin, it is obviously desirable to have an estimate of requirements or desirable levels of intake; either saturation of erythrocyte pyruvate-CoA carboxylase with its coenzyme or, preferably, 3-hydroxy-isovalerate excretion (perhaps after a test dose of leucine) will provide an index of adequacy.

There still seems to be no way of assessing pantothenate status. 


\section{References}

Bannister DW (1976) The biochemistry of fatty liver and kidney syndrome: biotin-mediated restoration of hepatic gluconeogenesis in vitro and its relationship to pyruvate carboxylase activity. Biochemical Journal 156, 167-173.

Barshop BA, Yoshida I, Ajami A, Sweetman L, Wolff JA, Sweetman FR, Prodanos C, Smith M \& Nyhan WL (1991) Metabolism of $1-\left[{ }^{13} \mathrm{C}\right]$ propionate in vivo in patients with disorders of propionate metabolism. Pediatric Research 30, 15-22.

Berthon HA, Kuchel PW \& Nixon PF (1992) High control coefficient of transketolase in the nonoxidative pentose phosphate pathway of human erythrocytes: NMR, antibody and computer simulation studies. Biochemistry 31, 12792-12798.

Bettendorf L, Hennuy B, De Clerck A \& Wins P (1994) Chloride permeability of rat brain membrane vesicles correlates with thiamine triphosphate content. Brain Research 652, 157-170.

Bettendorf L, Kolb HA \& Schoffeniels E (1993a) Thiamine triphosphate activates an anion channel of large unit conductance in neuroblastoma cells. Journal of Membrane Biology 136, 281288.

Bettendorf L, Peeters M, Wins P \& Schoffeniels E (1993b) Metabolism of thiamine triphosphate in rat brain: correlation with chloride permeability. Journal of Neurochemistry 60, 423434.

Bitsch R, Tôth-Dersi A \& Hoetzel D (1985) Biotin deficiency and biotin supply. Annals of the New York Academy of Sciences 447, 133-139.

Blansjaar BA, Zwang R \& Blijnberg BG (1991) No transketolase abnormalities in Wernicke-Korsakoff patients. Journal of Neurological Science 106, 88-90.

Blass JP \& Gibson GE (1977) Abnormality of a thiamine-requiring enzyme in patients with Wernicke-Korsakoff syndrome. New England Journal of Medicine 297, 1367-1370.

Blass JP, Sheu KF, Cooper AJ, Jung EH \& Gibson GE (1992) Thiamin and Alzheimer's disease. Journal of Nutritional Science and Vitaminology Special issue, 400-401.

Butterworth RF, Kril JJ \& Harper CG (1993) Thiamine-dependent enzyme changes in the brains of alcoholics: relationship to the Wernicke-Korsakoff syndrome. Alcoholism: Clinical and Experimental Research 17, 1084-1088.

Calingasan NY, Gandy SE, Baker H, Sheu KF, Smith JD, Lamb BT, Gearhart JD, Buxbaum JD, Harper C, Selkoe DJ, Proe DL, Sisodia SS \& Gibson CE (1996) Novel neuritic clusters with accumulations of amyloid precursor protein and amyloid precursor-like protein immunoreactivity in brain regions damaged by thiamine deficiency. American Journal of Pathology 149, 1063-1071.

Chauhan J \& Dakshinamurti K (1991) Transcriptional regulation of the glucokinase gene by biotin in starved rats. Journal of Biological Chemistry 266, 10035-10038.

Coy JF, Dubel S, Kioschis P, Thomas K, Micklem G, Delius H \& Poustka A (1996) Molecular cloning of tissue-specific transcripts of a transketolase-related gene: implications for the evolution of new vertebrate genes. Genomics 32, 309-316.

Donaldson WE (1985) Biotin effects on fatty acid synthesis in chicks. Annals of the New York Academy of Sciences 447, $105-111$.

Froguel P, Zouali H, Vionnet N, Velho G, Vaxillaire M, Sun F, Lesage S, Stoffel M, Takeda J \& Passa P (1993) Familial hyperglycemia due to mutations in glucokinase. Definition of a subtype of diabetes mellitus. New England Journal of Medicine 328, 697-702.

Harper C (1979) Wernicke's encephalopathy, a more common disease than realised (a neuropathological study of 51 cases).
Journal of Neurology, Neurosurgery and Psychiatry 42, 226231.

Héroux M, Raghavendra-Rao VL, Lavoie J, Richardson JS \& Butterworth RF (1996) Alteration of thiamine phosphorylation and of thiamine-dependent enzymes in Alzheimer's disease. Metabolic Brain Disease 11, 81-88.

Horwitt MK \& Kreisler O (1949) The determination of early thiamine deficient states by estimation of blood lactate and pyruvate after glucose administration and exercise. Journal of Nutrition 37, 411-427.

Hymes J, Fleischhauer K \& Wolf B (1995) Biotinylation of histones by human serum biotinidase: assessment of biotinyltransferase activity in sera from normal individuals and children with biotinidase deficiency. Biochemical and Molecular Medicine 56, 76-83.

Hymes J \& Wolf B (1996) Biotinidase and its roles in biotin metabolism. Clinica Chimica Acta 255, 1-11.

Jeyasingham MD, Pratt OE, Burns A, Shaw GK, Thomson AD \& Marsh A (1987) The activation of red blood cell transketolase in groups of patients especially at risk from thiamin deficiency. Psychological Medicine 17, 311-318.

Johnson AR, Hood RL \& Emery JL (1980) Biotin and the sudden infant death syndrome. Nature 285, 159-160.

Kirschbaum N, Clemons R, Marino KA, Sheedy G, Nguyen ML \& Smith CM (1990) Pantothenate kinase activity in livers of genetically diabetic mice $(d b / d b)$ and hormonally treated cultured rat hepatocytes. Journal of Nutrition 120, 1376-1386.

Kopinski JS, Leibholz J, Bryden WL \& Fogarty AC (1989) Biotin studies in pigs. 1. Biotin deficiency in the young pig. British Journal of Nutrition 62, 751-759.

Krause KH, Bonjour JP, Berlit P \& Kochen W (1985) Biotin status of epileptics. Annals of the New York Academy of Sciences 447, 297-313.

McCool BA, Plonk SG, Martin PR \& Singleton CK (1993) Cloning of human transketolase cDNAs and comparison of the nucleotide sequence of the coding region in Wernicke-Korsakoff and non-Wernicke-Korsakoff individuals. Journal of Biological Chemistry 268, 1397-1404.

Martin PR, McCool BA \& Singleton CK (1995) Molecular genetics of transketolase in the pathogenesis of the Wernicke-Korsakoff syndrome. Metabolic Brain Disease 10, 45-55.

Mastrogiacoma F, Bergeron C \& Kish SJ (1993) Brain alphaketoglutarate dehydrogenase complex activity in Alzheimer's disease. Journal of Neurochemistry 61, 2007-2114.

Mastrogiacoma F, Bettendorf L, Grisar T \& Kish SJ (1996) Brain thiamine, its phosphate esters and its metabolizing enzymes in Alzheimer's disease. Annals of Neurology 39, 585-591.

Matschinsky F, Liang Y, Kesavan P, Wang L, Froguel P, Velho G, Cohen D, Permutt MA, Tanizawa Y \& Jetton TL (1993) Glucokinase as pancreatic beta cell glucose sensor and diabetes gene. Journal of Clinical Investigation 92, 2092-2098.

Matsumoto M, Kuhara T, Inoue Y, Shinka T \& Matsumoto I (1991) Abnormal fatty acid metabolism in patients in hopantenate therapy during clinical episodes. Journal of Chromatography 562, 139-145.

Matsumoto T, Hardy RW \& Stickney RR (1994) Pantothenate deficiency detection in rainbow trout (Oncorhynchus mykiss). Journal of Nutrition 124, 430-435.

Meador K, Loring D, Nichols M, Zamrini E, Rivner M, Posas H, Thompson E \& Moore E (1993) Preliminary findings of high dose thiamine in dementia of Alzheimer's type. Journal of Geriatric Psychiatry and Neurology 6, 222-229.

Mimori Y, Katsuoka H \& Nakamura S (1996) Thiamine therapy in Alzheimer's disease. Metabolic Brain Disease 11, 89-94.

Mock DM (1991) Skin manifestations of biotin deficiency. Seminars in Dermatology 10, 296-302. 
Mock DM, Johnson SB \& Holman RT (1988) Effects of biotin deficiency on serum fatty acid composition: evidence for abnormalities in humans. Journal of Nutrition 118, 342-348.

Mock NI, Malik MI, Stumbo PJ, Bishop WP \& Mock DM (1997) Increased urinary excretion of 3-hydroxyisovalerate and decreased urinary excretion of biotin are sensitive early indicators of decreased biotin status in experimental biotin deficiency. American Journal of Clinical Nutrition 65, 951-958.

Mock NI \& Mock DM (1992) Biotin deficiency in rats: disturbances of leucine metabolism are detectable early. Journal of Nutrition 122, 1493-1499.

Mukherjee AB, Svoronos S, Ghazanfari A, Martin PR, Fisher A, Roecklein B, Rodbard D, Staton R, Behar D \& Berg CJ (1987) Transketolase abnormality in cultured fibroblasts from familial chronic alcoholic men and their male offspring. Journal of Clinical Investigation 79, 1039-1043.

Nakahiro M, Fujita N, Fukuchi I, Saito K, Nishimura T \& Yoshida H (1985) Pantoyl- $\gamma$-aminobutyrate facilitates cholinergic function in the central nervous system. Journal of Pharmacology and Experimental Therapeutics 232, 501-506.

Nixon PF, Kaczmarek MJ, Tate J, Kerr RA \& Price J (1984) An erythrocyte transketolase isoenzyme pattern associated with the Wernicke-Korsakoff syndrome. European Journal of Clinical Investigation 14, 278-281.

Noda S, Haratake J, Sasaki A, Ishii N, Umezaki H \& Horie A (1991) Acute encephalopathy with hepatic steatosis induced by pantothenate antagonist, calcium hopantenate, in dogs. Liver 11, 134-142.

Nolan KA, Black RS, Sheu KF, Langberg J \& Blass JP (1991) A trial of thiamine in Alzheimer's disease. Archives of Neurology 8, 81-83.

Nyhan WL (1987) Inborn errors of biotin metabolism. Archives of Dermatology 123, 1696a-1698a.

Page MG, Ankoma-Sey V, Coulson WF \& Bender DA (1989) Brain glutamate and $\gamma$-aminobutyrate (GABA) metabolism in thiamin-deficient rats. British Journal of Nutrition 62, 245-253.

Pietrzik K, Hesse C \& Hötzel D (1975) Influencing of acetylation and corticosterone biosynthesis through long-term pantothenate deficiency in rats. International Journal of Vitamin and Nutrition Research 45, 251-261.

Proud VK, Rizzo WB, Patterson JW, Heard GS \& Wolf B (1990) Fatty acid alterations and carboxylase deficiencies in the skin of biotin-deficient rats. American Journal of Clinical Nutrition 51, 853-858.

Reed LJ (1976) Regulation of mammalian pyruvate dehydrogenase complex by phosphorylation and dephosphorylation. In Thiamine, pp. 19-30 [GC Gubler, M Fujiwara and PM Dreyfus, editors]. New York: Wiley.
Reibel DK, Wyse BW, Berkich DA \& Neely JR (1982) Coenzyme A metabolism in pantothenate deficient rats. Journal of Nutrition 112, 1144-1150.

Scriver R, MacKenzie S, Chow CL \& Delvin E (1971) Thiamineresponsive maple-syrup-urine disease. Lancet $\mathbf{i}, 310-312$.

Smith CM, Narrow CM, Kendrick ZV \& Steffen C (1987) The effect of pantothenate deficiency in mice on their metabolic response to fast and exercise. Metabolism 36, 115-121.

Stryer L (1995) Biochemistry, 4th ed. New York: W. H. Freeman \& Co.

Thornber EJ, Dunlop RH \& Gawthorne JM (1980) Thiamin deficiency in the lamb: changes in thiamin phosphate esters in the brain. Journal of Neurochemistry 35, 713-717.

Thurnham DI (1981) Red cell enzyme tests of vitamin status: do marginal deficiencies have any physiological significance? Proceedings of the Nutrition Society 40, 155-163.

Vas A, Gachalyi B \& Kaldor A (1990) Pantothenic acid, acute ethanol consumption and sulphadimidine acetylation. International Journal of Pharmacology, Therapeutics and Toxicology 28, 111-114.

Volpe JJ \& Vagelos PR (1973) Fatty acid synthetase of mammalian brain, liver and adipose tissue: regulation by prosthetic group turnover. Biochimica et Biophysica Acta 326, 293-304.

Wang JJ, Martin PR \& Singleton CK (1997) A transketolase assembly defect in a Wernicke-Korsakoff syndrome patient. Alcoholism: Clinical and Experimental Research 21, 576-580.

Watanabe T, Dakshinamurti K \& Persaud TV (1995) Biotin influences palatal development of mouse embryos in organ culture. Journal of Nutrition 125, 2114-2121.

Watanabe T \& Endo A (1984) Teratogenic effects of avidininduced biotin deficiency in mice. Teratology 30, 91-94.

Watkins BA (1988) Influences of biotin deficiency and dietary trans-fatty acids on tissue lipids in chickens. British Journal of Nutrition 61, 99-111.

Webster MJ, Scheett TP, Doyle MR \& Branz M (1997) The effect of a thiamin derivative on exercise performance. European Journal of Applied Physiology 75, 520-524.

Wittwer CT, Beck S, Peterson M, Davidson R, Wilson DE \& Hansen RG (1990) Mild pantothenate deficiency in rats elevates serum triglyceride and free fatty acid levels. Journal of Nutrition 120, 719-725.

Zhang H, Osada K, Sone H \& Furukawa Y (1997) Biotin administration improves impaired glucose tolerance of streptozotocin-induced diabetic Wistar rats. Journal of Nutritional Science and Vitaminology 43, 271-280.

Zubaran C, Fernandes JG \& Rodnight R (1997) WernickeKorsakoff syndrome. Postgraduate Medical Journal 73, 27-31. 